\title{
Cough Threshold to Inhaled Tartaric Acid and Bronchial Responsiveness to Methacholine in Patients with Asthma and Sino-bronchial Syndrome
}

\author{
Masaki Fujimura, Sayuri Sakamoto, Yumie Kamro, ${ }^{*}$ Motoyasu Saito, Yasushi Miyake, \\ Masahide YAsur and Tamotsu MatsudA
}

\begin{abstract}
To evaluate the effect of chronic airway inflammation on cough sensitivity and bronchial responsiveness, we measured the cough threshold to tartaric acid and bronchial responsiveness to methacholine $\left(\mathrm{PC}_{20}-\mathrm{FEV}_{1}\right)$ in 13 asthmatic, 13 bronchitic (sino-bronchial syndrome) and 49 healthy non-atopic subjects. All subjects were non-smokers. The geometric mean value of the cough threshold was $9.55,5.62$ and $12.3 \%$ in asthmatic, bronchitic and normal subjects, respectively. The value in bronchitic subjects was significantly $(p<0.02)$ lower than that in normal subjects. The geometric mean value of $\mathrm{PC}_{20}-\mathrm{FEV}_{1}$ in asthmatic subjects $(0.63 \mathrm{mg} / \mathrm{ml})$ was significantly lower than those in bronchitic $(8.7 \mathrm{mg} / \mathrm{ml})(\mathrm{p}<0.01)$ and normal subjects $(21.4 \mathrm{mg} / \mathrm{ml})(\mathrm{p}<0.01)$. There was no correlation between cough threshold and $\mathrm{PC}_{20}-\mathrm{FEV}_{1}$ values [correlation coefficient $(r)=0.06, p>0.1]$. These results indicate that cough sensitivity is potentiated by chronic airway inflammation in bronchitis but not in asthma and suggest that cough sensitivity and bronchial responsiveness may be independently potentiated by different mechanisms resulting from chronic airway inflammation.
\end{abstract}

(Internal Medicine 31: 17-21, 1992)

Key words: cough sensitivity, chronic airway inflammation

\section{Introduction}

Cough is a major respiratory manifestation. It has been established that cough can be the sole manifestation in asthmatic patients with bronchial hyperresponsiveness $(1,2)$, a feature of bronchial asthma (3). Cigarette smoking appears not to have a definite influence on bronchial responsiveness in population data limited to young and midddle-aged adults $(4,5)$, but bronchial responsiveness has been shown to be potentiated in older cigarette smokers (6-9). On the other hand, Pounsford and Saunder (10) have reported that moderate smokers tend to cough more than non-smokers following the inhalation of citric acid. In addition, Taylor and colleagues (11) have demonstrated that the cough threshold to citric acid correlates with the bronchial responsiveness to histamine in cigarette smokers. Consequently, it has been suggested that there is some connection between cough sensitivity and bronchial responsiveness. It is likely that cigarette smoking could potentiate both the sensitivity of airway cough receptors and the bronchial responsiveness to inhaled bronchoconstrictors by inducing chronic airway inflammation (12) and/or increasing airway mucosal permeability (13). Bronchial hyperresponsiveness, which is characteristic of asthma (3), is considered to be a consequence of chronic airway inflammation and damage to airway epithelium (14).

This study was designed to examine the relationships between chronic airway inflammation, cough sensitivity and bronchial responsiveness. We measured the cough threshold to inhaled tartaric acid, a chemostimulant similar to citric acid, and the bronchial responsiveness to methacholine in patients with asthma and sino-bronchial syndrome (15) and healthy non-smokers.

From The Third Department of Internal Medicine, Kanazawa University School of Medicine, Kanazawa and *The Central Clinical Laboratory, Kanazawa University Hospital, Kanazawa

Received for publication September 14, 1990; Accepted for publication April 2, 1991

Reprint requests should be addressed to Masaki Fujimura, MD, The Third Department of Internal Medicine, Kanazawa University School of Medicine, 13-1 Takara-machi, Kanazawa 920, Japan 


\section{Subjects and Methods}

Subjects. Thirteen asthmatic patients (five men and eight women), with a mean age of 48.4 (range, 27 to 67) yr, 13 patients with sino-bronchial syndrome (six men and seven women), with a mean age of 58.3 (range, 35 to 73) yr, and 49 healthy non-atopic subjects ( 22 men and 27 women), with a mean age of 22.0 (range, 20 to 28) yr, participated in this study (Table 1 ). All subjects were non-smokers and had not suffered from a viral infection for at least $4 \mathrm{wk}$ prior to the study. Informed consent was obtained from all subjects after the purpose of the study had been explained. This study was approved by the ethics committee of our university.

Bronchial asthma was diagnosed based on the following three criteria: 1) a history of recurrent episodes of wheezing, 2) reversible airway obstruction previously documented by a physician, and 3) an improvement of $15 \%$ or more in forced expiratory volume in $1 \mathrm{~s}\left(\mathrm{FEV}_{1}\right)$ after inhalation of $300 \mu \mathrm{g}$ salbutamol sulphate. Three men and three women had extrinsic asthma who showed positive allergen skin tests and/or specific IgE antibodies. Two men and five women had intrinsic asthma with no familial history of allergic diseases, no increased levels of specific IgE antibodies, and no positive skin test to 10 common allergens.

Sino-bronchial syndrome (15) was diagnosed based on the following criteria: 1) a history of chronic bronchitis (16), and 2) the presence of chronic sinusitis. Chronic sinusitis was diagnosed by otolaryngologists based on the symptoms (postnasal drip, nasal discharge and nasal obstruction), physical examination and roentogenogram. Among the sino-bronchial patients, seven patients had diffuse bronchiectasis (17) documented by chest roentgenogram, chest CT scan, bronchofiberscopy and bronchography. Five patients had chronic simple bronchitis and one patient had chronic obstructive bronchitis (16).

Normal subjects were chosen from 86 healthy students from the School of Paramedicine and School of Medicine in our university who visited our laboratory for training

Table 1. Subject Profile

\begin{tabular}{|c|c|c|c|}
\hline & $\begin{array}{l}\text { Bronchial } \\
\text { asthma }\end{array}$ & $\begin{array}{l}\text { Sino-bronchial } \\
\text { syndrome }\end{array}$ & Normal \\
\hline Male:Female & $5: 8$ & $6: 7$ & $22: 27$ \\
\hline Age $\quad(y r)$ & $48.4 \pm 4.0$ & $58.3 \pm 3.2$ & $22.0 \pm 0.2$ \\
\hline FVC & $3.57 \pm 0.26$ & $3.01 \pm 0.20$ & $4.11 \pm 0.13$ \\
\hline$\% \mathrm{FVC}$ & $112 \pm 4$ & $102 \pm 4$ & $103 \pm 1$ \\
\hline $\mathrm{FEV}_{1}$ & $2.41 \pm 0.21$ & $2.22 \pm 0.14$ & $3.69 \pm 0.11$ \\
\hline$\% \mathrm{FEV}_{1} \quad(\%)$ & $82 \pm 3$ & $89 \pm 5$ & $104 \pm 2$ \\
\hline $\mathrm{FEV}_{1} / \mathrm{FVC} \quad(\%)$ & $67 \pm 3$ & $75 \pm 3$ & $90 \pm 1$ \\
\hline \multirow[t]{2}{*}{ Type of disease } & Ext: 7 & With BE: 7 & \\
\hline & Int: 6 & Without BE: 6 & \\
\hline
\end{tabular}

Data expressed as mean \pm SEM.

FVC, forced vital capacity; $\mathrm{FEV}_{1}$, forced expiratory volume in $1 \mathrm{~s}$; Ext, extrinsic asthma; Int, intrinsic asthma; $\mathrm{BE}$, bronchiectasis. in the technique of pulmonary function testing. All subjects were non-smokers and non-atopic with neither a past history nor familial history of allergic diseases.

Measurement of cough threshold and bronchial responsiveness were performed when their symptoms were mild and stable while they were administered oral theophylline, oral and aerosol $\beta_{2}$-adrenergic stimulants and mucolytic agents, but not steroids. All medication was stopped at 9:00 PM the previous day to allow a washout time of $12 \mathrm{~h}$ or more before the measurements.

Measurement of cough sensitivity. Cough sensitivity was evaluated by a tartaric acid inhalation test (18). Tartaric acid (Wako Pure Chemical Industries, Ltd., Tokyo) was dissolved in physiological saline to make solutions of $0.156,0.312,0.625,1.25,2.5,5,10,20,40$ and $80 \%$. Each subject inhaled a control solution of physiological saline followed by progressively increasing concentrations of the tartaric acid solution. While wearing a nose clip, solutions were inhaled every minute for a period of $15 \mathrm{~s}$ by tidal breathing through a Bennett Twin nebulizer (3012-60 cc, Puritan-Bennett Co., Carlsbad, CA, USA), and increasing concentrations were inhaled until five or more coughs were elicited. The nebulizer output was $0.21 \mathrm{ml} / \mathrm{min}$. The cough threshold was defined as the lowest concentration of tartaric acid that elicited five or more coughs.

Spirometry was carried out before and after the tartaric acid inhalation test in 24 normal subjects, in order to examine whether tartaric acid of cough threshold induces bronchoconstriction.

Measurement of bronchial responsiveness. Bronchial responsiveness was evaluated by methacholine challenge (19) at the same time as the measurement of the cough threshold but on a separate day within 2 wk. Methacholine chloride was dissolved in physiological saline to make solutions of $0.04,0.08,0.16,0.31,0.63,1.25,2.5,5,10$, $20,40,80$ and $160 \mathrm{mg} / \mathrm{ml}$. Saline and methacholine were inhaled from a Devilbiss 646 nebulizer (Devilbiss Co., Somerset, PA, USA) operated by compressed air at 51/ $\min$. The nebulizer output was $0.28 \mathrm{ml} / 2 \mathrm{~min}$. Saline was inhaled first for $2 \mathrm{~min}$ and the forced expiratory volume in $1 \mathrm{~s}\left(\mathrm{FEV}_{1}\right)$ was measured on a dry wedge spirometer (Transfer Test, P.K. Morgan Ltd., England). When the change in $\mathrm{FEV}_{1}$ from the baseline after inhalation of saline was $10 \%$ or less in all subjects, inhalation of methacholine was started. Methacholine was inhaled for 2 min by tidal breathing wearing a nose clip, and this was followed immediately by spirometry. Increasing concentrations were inhaled until a fall of $20 \%$ or more in $\mathrm{FEV}_{1}$ occurred. The measured values were plotted on semilogarithmic graph paper and the methacholine provocative concentration producing a $20 \%$ fall in $\mathrm{FEV}_{1}$ $\left(\mathrm{PC}_{20}-\mathrm{FEV}_{1}\right)$ was calculated.

Data analysis. The cough threshold and methacholine $\mathrm{PC}_{20}-\mathrm{FEV}_{1}$ values were expressed as geometric means with the geometric standard error of the mean (GSEM) 


\section{Cough and Bronchial Responsiveness}

expressed as a factor. Values for the baseline forced vital capacity (FVC) and $\mathrm{FEV}_{1}$ were reported as arithmetic means and standard errors of the mean (SEM).

Geometric mean values of the cough threshold and $\mathrm{PC}_{20}-\mathrm{FEV}_{1}$ were compared among asthmatic, bronchitic and normal subjects by the unpaired t test. A p value of 0.05 or less was taken as significant. To examine the relationship between cough sensitivity and bronchial responsiveness, linear regression and correlation analysis were employed for logarithmic values of the cough threshold and $\mathrm{PC}_{20}-\mathrm{FEV}_{1}$.

\section{Results}

A cough threshold was obtained in 72 subjects. No cough was elicited in three normal subjects by the final concentration of tartaric acid $(80 \%)$. The cough threshold values for these three were assumed to be $100 \%$ for statistical analysis. Individual values of the cough threshold are shown in Fig. 1. The geometric mean value of the cough threshold was $9.55 \%$ (GSEM, 1.35), 5.62\% (GSEM, 1.35) and $12.3 \%$ (GSEM, 1.17) in asthmatic, bronchitic and normal subjects, respectively. The value in bronchitic subjects was significantly $(p<0.02)$ lower than that in normal subjects. There was no significant difference in the cough threshold between asthmatic and normal subjects. Individual values of $\mathrm{FEV}_{1}$ before and

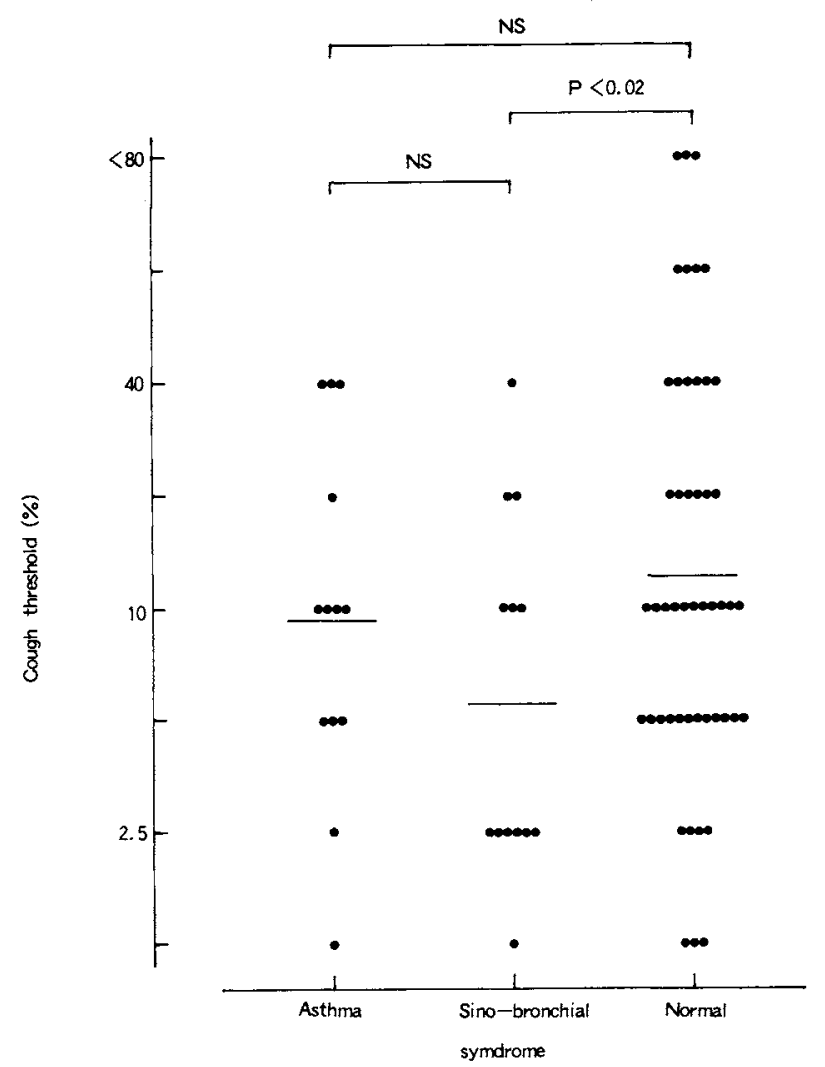

Fig. 1. Cough threshold value to inhaled tartaric acid in asthmatic, bronchitic and normal subjects. NS, no significant difference. after the measurement of cough threshold are shown in Fig. 2. The $\mathrm{FEV}_{1}$ values were not significantly altered by the cough threshold concentration of tartaric acid in normal subjects (from $2.93 \pm 0.05$ to $2.91 \pm 0.051$ ).

A methacholine $\mathrm{PC}_{20}-\mathrm{FEV}_{1}$ value was obtained in 55 subjects. A $20 \%$ or greater fall in $\mathrm{FEV}_{1}$ was not achieved

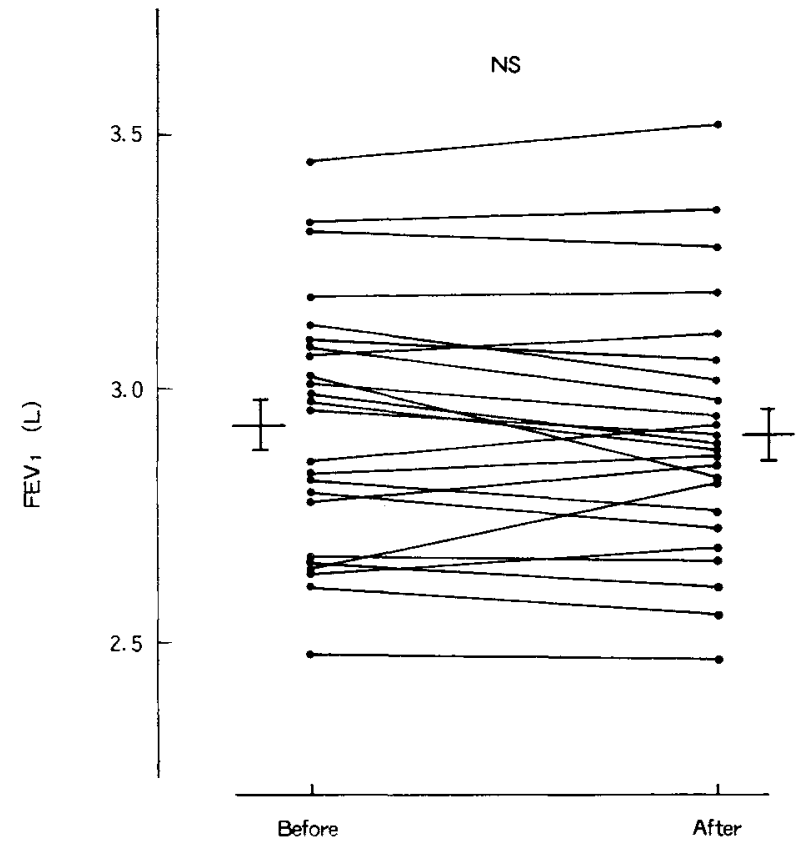

Fig. 2. FEV $V_{1}$ values before and after the measurement of tartaric acid cough threshold in 24 normal subjects. NS, no significant difference.

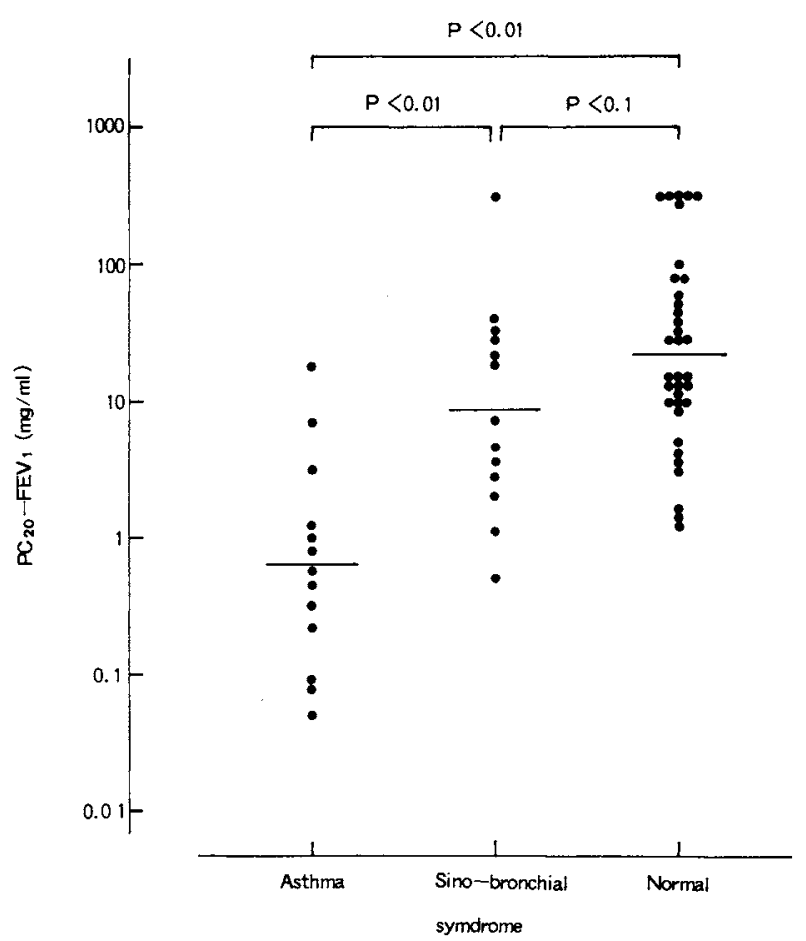

Fig. 3. Bronchial responsiveness to methacholine in asthmatic, bronchitic and normal subjects. $\mathrm{PC}_{20}-\mathrm{FEV}_{1}$, provocative concentration of methacholine causing a $20 \%$ fall in forced expiratory volume in $1 \mathrm{~s}$. 


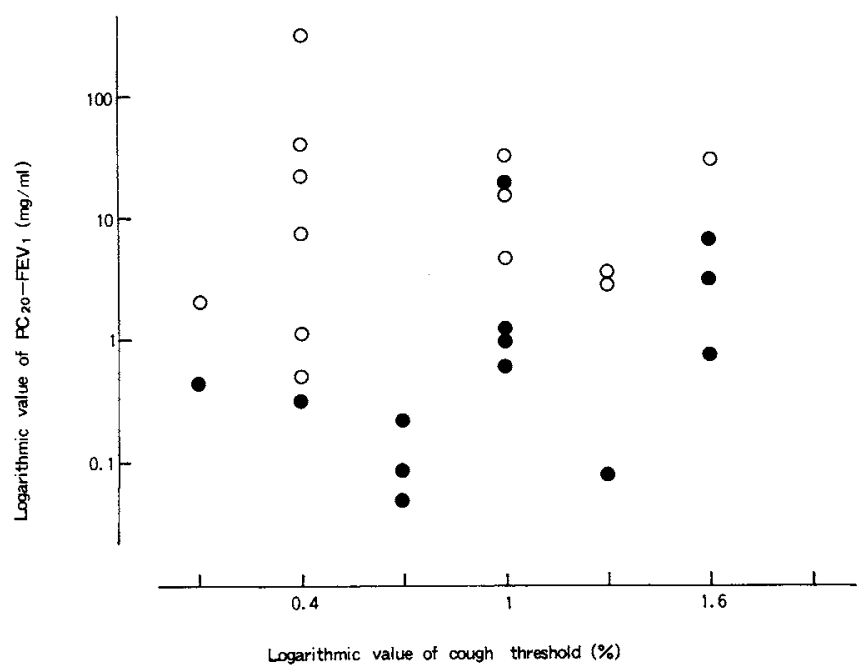

Fig. 4. Relationship between the cough threshold to inhaled tartaric acid and bronchial responsiveness to methacholine in asthmatic (closed circles) and bronchitic (open circles) subjects. There was no correlation between the logarithmic values of cough threshold and $\mathrm{PC}_{20}-\mathrm{FEV}_{1}$ [correlation coefficient $(\mathrm{r})=0.06, \mathrm{p}>0.1$ ]

by the final concentration of methacholine $(160 \mathrm{mg} / \mathrm{ml})$ in one bronchitic and six normal subjects. The $\mathrm{PC}_{20^{-}}$ $\mathrm{FEV}_{1}$ values for these seven subjects were assumed to be $320 \mathrm{mg} / \mathrm{ml}$ for statistical analysis. Individual values of $\mathrm{PC}_{20}-\mathrm{FEV}_{1}$ are shown in Fig. 3. The geometric mean value of the $\mathrm{PC}_{20}-\mathrm{FEV}{ }_{1}$ was $0.63 \mathrm{mg} / \mathrm{ml}$ (GSEM, 1.62), $8.7 \mathrm{mg} / \mathrm{ml}$ (GSEM, 1.62) and $21.4 \mathrm{mg} / \mathrm{ml}$ (GSEM, 1.29) in asthmatic, bronchitic and normal subjects, respectively. The value in asthmatic subjects was significantly lower than those in bronchitic $(\mathrm{p}<0.01)$ and normal subjects $(\mathrm{p}<0.01)$. The $\mathrm{PC}_{20}-\mathrm{FEV}_{1}$ was lower in bronchitic subjects than in normal subjects, but it was not significant.

The correlation between cough sensitivity and bronchial responsiveness in asthmatic and bronchitic subjects is shown in Fig. 4. No correlation was observed between the cough threshold value to inhaled tartaric acid and the $\mathrm{PC}_{20}-\mathrm{FEV}_{1}$ value to methacholine in the subjects [correlation coefficient $(\mathrm{r})=0.06, \mathrm{p}>0.1]$.

\section{Discussion}

It has been well known that cough can be the sole manifestation in some asthmatic patients $(1,2)$. Taylor and co-workers (11) have shown that the cough threshold to citric acid correlates with the bronchial responsiveness to histamine in cigarette smokers. Ongoing airway inflammation is a pathological change both in asthmatic (14) and in smoking subjects (12). Consequently, it has been suggested that there is relationship between cough sensitivity and bronchial responsiveness. On the other hand, Gibson and co-workers (20) reported that those patients presenting with only cough had no bronchial hyperresponsiveness, and were diagnosed as having eosinophilic bronchitis without asthma. Therefore they have speculated that there is no direct correlation between airway eosinophil infiltration and bronchial hyperresponsiveness. The investigation is very suggestive of the need to reconsider the relationship between cough sensitivity and bronchial responsiveness.

The present study was designed to evaluate the relationship. The cough threshold to tartaric acid aerosol and bronchial responsiveness to methacholine were measured in non-smokers with asthma and sino-bronchial syndrome, during ongoing airway inflammation. Nonsmokers were selected for this study because smoking is one of the factors influencing both cough sensitivity (10, $11,18)$ and bronchial responsiveness $(6-9,11)$. In this study, we used tartaric acid as a cough receptor stimulator. Tartaric acid is a chemostimulant and induces cough by stimulating cough receptors as well as citric acid. As shown in this study, tartaric acid does not produce significant bronchoconstriction at the cough threshold concentration eliciting five or more coughs.

This study demonstrated that airway cough receptors were more sensitive in bronchitic subjects than in normal subjects, while there was no significant difference between the cough sensitivities of normal and asthmatic subjects. Bronchial responsiveness was shown to be significantly potentiated in asthmatic subjects compared with bronchitic and normal subjects, which agrees with an important feature of asthma (3). In addition, there was no correlation between the cough sensitivity and bronchial responsiveness in asthmatic and bronchitic subjects. These findings indicate that cough sensitivity is potentiated by chronic airway inflammation in bronchitic subjects, but not in asthmatic subjects, and suggests that cough sensitivity and bronchial responsiveness may be independently potentiated by different mechanisms resulting from chronic airway inflammation. Regarding bronchial responsiveness, we (21) have reported that the inflammatory mediators involved in bronchial responsiveness are different in asthma and in bronchitis since the thromboxane synthetase inhibitor OKY-046 (22), reduces the bronchial responsiveness to methacholine in asthmatic subjects but not in bronchitic, bronchiectatic or normal subjects, while the cyclooxygenase inhibitor, indomethacin, attenuates bronchial responsiveness only in bronchiectatic subjects. It has been suggested that thromboxane $\mathrm{A}_{2}$ is involved in the development of bronchial hyperresponsiveness in asthma and that bronchoconstrictor prostaglandins, other than thromboxane $\mathrm{A}_{2}$, may potentiate the bronchial responsiveness in bronchiectasis. Thus, it is likely that the factors contributing to cough sensitivity in asthma may be different from those acting in bronchitis and this may explain the absence of a strong correlation between cough sensitivity and bronchial responsiveness in asthma and bronchitis. However, it is not known which mechanisms may operate to potentiate cough sensitivity in bronchitis. Further studies are therefore needed to elucidate these 


\section{Cough and Bronchial Responsiveness}

mechanisms.

The source of support in the form of grants: Grant-in-Aid for the Ministry of Education, Science and Culture (No. 01770510) of Japan.

\section{References}

1) McFadden ER. Exertional dyspnea and cough as preludes to acute attacks of bronchial asthma. N Engl J Med 292: 555, 1975.

2) Corrao WM, Braman SS, Irwin RS. Chronic cough as the sole presenting manifestation of bronchial asthma. N Engl J Med 300: $633,1979$.

3) Boushey HA, Holtzman MJ, Sheller JR, Nadel JA. Bronchial hyperreactivity. Am Rev Respir Dis 121: 389, 1989.

4) Rijcken B, Schouten JP, Weiss ST, Speizer FE, Van der Lende $\mathrm{R}$. The relationship of nonspecific bronchial responsiveness to respiratory symptoms in a random population sample. Am Rev Respir Dis 136: 62, 1987.

5) Cockcroft DW, Berscheid BA, Murdock KY. Bronchial response to inhaled histamine in asymptomatic young smokers. Eur $\mathbf{J}$ Respir Dis 64: 207, 1983.

6) Sparrow D, O'Connor G, Colton T, Barry CL, Weiss ST. The relationship of nonspecific bronchial responsiveness to the occurrence of respiratory symptoms and decreased levels of pulmonary function. The normative aging study. Am Rev Respir Dis 135: 1255, 1987.

7) Casale TB, Rhodes BJ, Donnelly AL, Weiler JM. Airway responses to methacholine in asymptomatic nonatopic cigarette smokers. J Appl Physiol 62: 1888, 1987.

8) Cerveri ISA, Bruschi C, Zoia MC, Zoia MC, et al. Smoking habit and bronchial reactivity in normal subjects. A population-based study. Am Rev Respir Dis 140: 191, 1989.

9) Kabiraj MU, Simonsson BG, Groth S, Bjorklund A, Bulow K, Lindell SE. Bronchial reactivity, smoking, and alpha $a_{1}$-antitrypsin. A population-based study of middle-aged men. Am Rev Respir Dis 126: 864, 1982.
10) Pounsford $\mathbf{J C}$, Saunder KB. Cough response to citric acid aerosol in occasional smokers. Br Med J 293: 1528, 1986.

11) Taylor DR, Reid WD, Pare PD, Fleetham JA. Cigarette smoke inhalation patterns and bronchial reactivity. Thorax 43: 65, 1988.

12) Niewoehner DE, Kleinerman J, Rice DB. Pathologic changes in the peripheral airways of young cigarette smokers. N Engl J Med 291: 755, 1974.

13) Kennedy SM, Elwood RK, Wiggs BJR, Pare PD, Hogg JC. Increased airway mucosal permeability of smokers: Relationship to airway reactivity. Am Rev Respir Dis 129: 143, 1984.

14) Barnes PJ, Chung KF, Page CP. Inflammatory mediators and asthma. Pharmacol Rev 40: 49, 1988.

15) Mcbride JT, Brooks JG. Sinobronchial syndrome. Ear Nose Throat J 63: 177, 1984.

16) American Thoracic Society. Standards for the diagnosis and care of patients with chronic obstructive pulmonary disease (COPD) and asthma. Am Rev Respir Dis 136: 225, 1987.

17) Welch MH. Bronchiectasis. in: Pulmonary Medicine, Guenter CA, Welch MH, Eds. 2nd ed. JB Lippincott Company, Philadelphia, 1982, p. 743.

18) Fujimura M, Sakamoto S, Kamio $Y$, Matsuda T. Sex difference in the inhaled tartaric acid cough threshold in non-atopic subjects. Thorax 45: 633, 1990.

19) Makino S, Kobayashi S, Miyamoto $T$, et al. Standard methods of provocation tests for asthma and hypersensitivity pneumonitis. Jpn J Allergol 31: 1074, 1982.

20) Gibson PG, Dolovich J, Denburg J, Ramsdale EH. Chronic cough: Eosinophilic bronchitis without asthma. Lancet i: 1346, 1989.

21) Fujimura M, Sakamoto S, Matsuda T. Attenuating effect of a thromboxane synthetase inhibitor (OKY-046) on bronchial responsiveness to methacholine is specific to bronchial asthma. Chest 98: 656, 1990.

22) Naito J, Komatsu H, Ujiie A, Hamano A, Kubota T, Tsuboshima M. Effects of thromboxane synthetase inhibitors on aggregation of rabbit platelets. Eur J Pharmacol 91: 41, 1983. 